\title{
FINANCIAL AND SOCIAL CHALLENGES FACING PENSIONERS LIVING ALONE BELOW THE POVERTY LINE DURING THE COVID-19 PERIOD: THE CASE OF GEORGIA
}

\author{
Anastasia Kitiashvili, Tamar Makharadze \\ Ivane Javakhishvili Tbilisi State University, Georgia \\ E-mail: anastasia.kitiashvili@tsu.ge, Tamar.Makharadze@tsu.ge
}

\begin{abstract}
Restrictions, physical distancing and lockdown imposed during Covid-19 are associated with many challenges such as financial shortages and lack of social relationships, which have been particularly damaging for vulnerable groups dependent on others.

This research aims to study financial and social challenges faced by one of the vulnerable social groupspensioners living alone below the poverty line during the covid-19 period in four Georgia municipalities (Bolnisi, Dmanisi, Tianeti and Kaspi) in July-August 2020. The survey was conducted with 475 respondents (confidence level 95, interval 4), but 11 questionnaires were discarded due to technical deficiencies. The analysis was performed on 464 data. The study used available sampling where gender (strata) representation was maintained. $78.6 \%$ were female and $21.14 \%$ male.

Overall, the elderly is a fairly vulnerable group in municipalities and across the country. The biggest problem during the pandemic period was a lack of financial resources. The study participants' primary income source is social assistance and various pensions; Thus, the elderly people are financially dependent on state aid.

The elderly have limited social relationships; They rarely interact with neighbors, much less with relatives, and even less with friends. The elderly rarely go to the city or village center either. Limited social networking and activities affect the mental health of the elderly. Such a situation is especially noteworthy in a pandemic. There is a positive correlation between limited access to technologies and lack of financial resources that plays a vital role in social relationships among the elderly; Those elderly who cannot afford access to computer/internet and telephone reported higher isolation levels.
\end{abstract}

Keywords: social isolation, Covid-19, pensioners living alone, under poverty line

\section{Introduction}

Older people are one of the most vulnerable groups worldwide, especially in developing countries (World Health Organization, 2011), due to various reasons such as low incomes, mostly filled with pensions (Sumbadze et al., 2020), health-related factors (United Nations, 2015; World Health Organization, 2011; United Nations, 2020), social stigma or discrimination (United Nations, 2020). As the elderly are a very heterogeneous group, it is not always possible to consider the needs of all age groups, which negatively affects their psychological and socio-economic status. 
OF PSYCHOLOGY

IN THE $21^{\text {st }}$ CENTURY

Vol. 15, No. 2, 2021

In the 21st century, the well-being of older people has become an influential agenda. Along with health care, great importance is attached to developing evidence-based services for the population and supporting healthy and active aging (United Nations, 2002; World Health Organization, 2017). The Madrid International Action Plan (2002) is the first international strategic document on population aging, focusing on creating the environment necessary for the development and wellbeing of the elderly (United Nations, 2002). This issue plays an essential role in the 2030 Sustainable Development Goals (United Nations, 2015). Developing a supportive environment for the elderly is also related to the Global Strategy and Action Plan adopted by the World Health Organization in 2017 (World Health Organization, 2017).

The COVID-19 pandemic conditions are no exception, and the elderly people are again at particular risk - (United Nations, 2020). The United Nations has analyzed the possible negative impact of the COVID-19 pandemic on the elderly. The policy document prepared by the UN identifies six areas in which the effects of the pandemic on the elderly may be reflected (United Nations, 2020):

1. Economic prosperity and reduced-income

2. Mental health, which is related to physical isolation

3. Involvement of responders for the elderly who work in the health care system increases the risk of infection;

4. Life and death - Fatalities are five times higher in the elderly.

5. Vulnerability because older people are frequent recipients of long-term care and require additional services.

6. Violence and neglect are already a problem; however, the risks of violence increase significantly under lockout and reduced care.

\section{Research Problem}

Based on the above, it is crucial to study the elderly living in Georgia in a pandemic period, especially in the regions and below the poverty that is especially vulnerable. It is essential to analyze the impact of the COVID-19 pandemic on their daily lives and social contacts. The study focused on social and economic aspects, as COVOD-19 has a significant effect on the population in both directions. The research data have been collected within the framework of the UN Joint Programme "Assisting the Georgian Government and Local Communities in Mitigating the Impact of COVID-19". The research has been supported by the United Nations Population Fund (UNFPA) Country Office in Georgia.

This research aimed to study financial and social challenges faced by pensioners living alone below the poverty line during the covid-19 period. The main focus of the study was to examine the extent to which older people experience financial storages and a lack of social contacts leading to social isolation due to lock down and restrictions during Covid-19.

\section{Research Focus}

The COVID-19 pandemic has led to the implementation of "social distancing" strategies to reduce the transmission of COVID-19. Social distancing has been applied amongst the whole population, including elderly people, who have experienced severe social isolation and loneliness with potentially serious mental and physical health consequences (Hwang at al., 2021). Social isolation has a well-documented negative impact on well-being in people of all ages, but this effect is enhanced in the elderly (Shankar at al., 2015; Windle., \& Woods, 2004).

Using technology to maintain relationships with friends, relatives or family have become a meaningful way to combat these adverse effects associated with prolonged loneliness and isolation. Digital tools and resources are a possible way to mitigate unintended consequences of social isolation, including during Covid-19. Virtual socialization and online events have become commonplace and have gone so far as to keep people from being isolated when locked up (Affo, 2020). Through online video chat, people have been able to social opportunities to avoid loneliness. Healthcare has 
also shifted to digital solutions, and online access to mental and physical health care has been quite

The positive impact of technology is reduced in the elderly (Friemel, 2016). The lack of modern technologies and skills to use them is considered by international researchers to be one of the important factors that increase the stress and loneliness of the elderly, especially in pandemic conditions (Domínguez-Rué \& Nierling, 2016; Viera et al., 2020). This unequal distribution of technological access and skills is known as the digital divide, and researchers suggest that it will continue to grow in the future. This leads to a paradoxical situation in which the population most affected by isolation is also the population least assisted by digital tools.

Though comprehensive research studies about the impact of the pandemic on the elderly in Georgia are not available, the challenges mentioned above are also relevant for older Georgian people because the elderly are one of the most vulnerable groups in Georgia (Public Defender of Georgia, 2019). The elderly population in Georgia is growing every year; in 2015 , the elderly population was $14.3 \%$ of the total population, in $2019-14.8 \%$ (Geostat, 2019), while in $2021-15.2 \%$. To increase the purpose and effectiveness of social assistance, the "Unified Database of Socially Vulnerable Families" was created in 2008, which, as of August 2020, comprises 969,293 people, of which 189,329 are aged 65 and over, and 15,213 people in the same age category in all four municipalities. According to the 2014 census, one in five women (19.8\%) and one in ten men (10.6\%) live alone, about 59 percent of women 65 and older, and 18.7 percent of men are widowed. The elderly population in Georgia is facing problems such as extreme poverty and lack of medical and social services (Public Defender of Georgia, 2019; Sumbadze et al., 2020; Bruni and Chitanava, 2017). The Public Defender of Georgia also reports discrimination based on the age of the elderly and violence against them (Public Defender of Georgia, 2019). International studies have also highlighted the rise of ageism in society in the face of pandemics - the main target of the pandemic is the predominance of the elderly, which negatively affects their image (Ayalon et.al). Social programs of local governments are less tailored to the needs of the elderly. According to a study conducted by researchers at Ivane Javakhishvili Tbilisi State University, the elderly living in the regions have additional requirements, often less considered by local governments (Sumbadze et al.).

\section{Research Methodology}

\section{General Background}

The desk research analyzed the general situation of the elderly in the country/ municipalities, COVID-19-related surveys and reports.

The survey research collected primary data directly from pensioners living alone below the poverty line registered in the targeted social assistance database of the Social Service Agency.

\section{Sample}

The survey was conducted in four municipalities: Bolnisi, Dmanisi, Tianeti and Kaspi municipalities in July-August 2020. In all four municipalities, the total number of pensioners living below the poverty line (less than 100,001 rating points) registered in the Social Services Agency's Targeted Social Assistance database was 2,276. The survey was conducted with 475 respondents (confidence level 95, interval 4), but 11 questionnaires were discarded due to technical deficiencies. The analysis was performed on 464 data.

In Georgia, $15 \%$ of the population is within the age category of 65 or above. Nearly half (46\%) of the elderly in the study are aged 70-79 years; This trend is maintained in all municipalities except Kaspi, where almost half of the population is younger and falls into the 60-69 age category.

More than 2/3 of the respondents are Georgians (78.8\%) in the sample as a whole and in all municipalities, while among the national minorities, Azerbaijanis predominate in Bolnisi and Dmanisi (30.3\% and 23.3\% respectively). 


\begin{tabular}{lc}
\hline Region & Sample Size \\
\hline Bolnisi & 98 \\
Dmanisi & 88 \\
Tianeti & 77 \\
Kaspi & 201 \\
Total & 464 \\
\hline
\end{tabular}

The study used available sampling in which gender (strata) representation was maintained. $79.6 \%$ of the whole population in all 4 regions were female and $20.4 \%$ were male, while $78.6 \%$ of women and $21.14 \%$ of men were surveyed in the study. Based on the selection of the given study (confidence level, small confidence interval, sex representation), the trends observed in the study are generally maintained among the elderly living in the target municipalities.

The survey was conducted at the respondents' house through a face-to-face interview. The interviewers themselves asked the respondents questions and filled out the questionnaires. The interview lasted about 25-30 minutes. All respondents had permission to make an "informed" consent to participate in the research. They were fully informed about the research aim and were able to stop participating in the study at any stage of the study.

\section{Instrument and Procedures}

The research questionnaire consisted mainly of closed-ended questions; The questionnaire included the following questions:

1. General information about the respondent;

2. Information about living conditions;

3. Information on the economic situation of the respondent; access to financial resources and technologies;

4. Information about the respondent's daily life activities, social isolation.

These concepts were measures based on the perception of the elderly.

Before developing the final version of the questionnaire, the instrument was piloted with 10 respondents in all four municipalities and after piloting it was processed accordingly. Before the survey, interviewers were trained and provided detailed information on conducting interview and completing the questionnaire.

\section{Data Analysis}

The survey data were entered into SPSS 26 program, which was used to perform quantitative data analysis; descriptive statistics was used to describe raw data using summary statistics (percentage, mean) and tables. There was also used Chi-square and correlational analysis using Spearmen's and Pearson's correlation.

Quantitative content analysis was performed on open-ended questions. 


\section{General Information about the Respondents}

In the study, almost half (49.4\%) of the elderly are widows; $5.2 \%$ of respondents have disability status.

Nearly half (46.4\%) of the elderly have children in a penitentiary institution, $26 \%$ have no children, and about $18.8 \%$ have died.

In general, the majority of older people in Georgia have received only basic, secondary or primary education, or have not completed their education (Geostat, 2021). In the present study, a low level of education achieved among the elderly was observed. $72 \%$ of respondents have secondary or lower education (secondary education predominates (39.1\%), 19.2\% have vocational education and only $8.9 \%$ have higher education. According to the general trend, most of the elderly in all municipalities have received secondary education (the rate varies from $38.4 \%$ to $50.6 \%$ ), while in Bolnisi primary education predominates (38.0\%).

\section{The Impact of the COVID-19 Global Pandemic on the Daily Lives and Well-being of Older People}

COVID-19 has affected people of all ages, but especially the elderly; The elderly were particularly vulnerable to the virus, which was reflected in their high mortality rate (United Nations, 2020); The mortality rate among the elderly aged 60-69 years was $3.6 \%$, among the elderly aged 70-79 years and 15\% among the elderly over the age of 80 years (World Health Organization, 2020). Pandemic prevention measures, especially social distancing, have contraindications, in particular, they negatively affect vulnerable groups, including the elderly - the social contacts of the elderly are already limited, and their isolation in a pandemic makes it more psychologically vulnerable. It is also important to note that much of the economic and social interaction occurs remotely, using digital technology in a pandemic, while older people have less access to modern technology and less skills to use it.

According to our study, among the most difficulties during the pandemic were financial problems, fear of disease, stress anxiety, and social isolation. (see table \#2).

\section{Table 2}

The Most Significant Difficulty in the Acute Period of COVID-19 (March-May 2020)

\begin{tabular}{lc}
\multicolumn{1}{c}{ Challenges } & $\%$ \\
\hline Isolation & 33 \\
Lack of communication & 22.5 \\
Lack of personal space & 1.7 \\
Immobility & 19.7 \\
Financial problems & 49.5 \\
Stress, anxiety & 34.3 \\
Fear of disease & 44.3 \\
That I became more dependent on others & 19.7 \\
\hline
\end{tabular}

It is crucial to inform the population during a pandemic and provide comprehensive information, especially to vulnerable groups. Older people often have mobility problems, and due to isolation and lack of information, they may find it challenging to take the necessary defensive measures - to buy products and services. The information may be vague or provided in a way that is not available to the elderly. Disseminating accurate information is very important in disease prevention in the elderly and informing the elderly what to do if they have suspicious symptoms. 
OF PSYCHOLOGY

IN THE $21^{\text {st }}$ CENTURY

Vol. 15, No. 2, 2021

According to the research, there were 3 primary sources of information about COVID-19: magazines and newspapers (98.8\%), television (57.5\%) and local -government (42.5\%).

The group of elderly people living alone belongs to the vulnerable group and, consequently, the share of the socially vulnerable predominates among them. The majority of respondents are socially vulnerable both in the entire sample (89.6\%) and in municipalities. Almost all respondents are socially vulnerable in Bolnisi (98\%) and Kaspi (97.5\%), while in Dmanisi and Tianeti - 75.6\% and $74 \%$, respectively.

Depending on the type of selection, it is not surprising that the vast majority of older people receive a pension, while the main source of income is social assistance $(80.8 \%)$. Far fewer female retirees have social assistance $(78.8 \%)$ than males $(88.9 \%)(\chi 2(4)=19.7, p<.05)$.

None of the older ones get income from work or business, only $3 \%$ get some income from selling their own agricultural products (see table \#3).

\section{Table 3}

Primary Sources of Income (Most Frequently Mentioned Answers)

\begin{tabular}{lc}
\hline & $\%$ \\
\hline Social support & 80.8 \\
Income from the sale of own-produced agricultural products & 3.0 \\
Regular help from relatives or loved ones & 2.4 \\
\hline
\end{tabular}

The vast majority of respondents $(84.7 \%)$ receive social assistance $(\chi 2(3)=10.7 ; p<.0540 \%)$. Most of the respondents do not find it difficult to pay utility bills, $31.3 \%$ have a variable situation periodically find it difficult to pay bills, and $23.3 \%$ find it challenging to pay. People with disabilities find it more difficult to pay utility bills than non-disabled people $(\chi 2(4)=17.09, p<.05)$. Since the main income of the elderly is social assistance and pensions, the elderly will likely be able to pay their utility bills from this source.

$60.3 \%$ of respondents often do not go to their destination due to a lack of travel money. Given the issues discussed in this article, it is not surprising that $63.2 \%$ of respondents rate their economic situation as bad / very bad; It is noteworthy that none of them assess their own financial crisis very well or well.

More than half of the respondents (52.4\%) assess the living conditions as "average", and a large part as "bad" (40.1\%).

The satisfaction of the respondents with the living conditions is appropriate to the assessment of living conditions; Naturally, the more positively the elderly evaluate living conditions, the more satisfied they are and vice versa $(r=1.08, p<.05)$; The largest part is neither satisfied nor dissatisfied $(54.3 \%)$ with living conditions. Only a few older $(0.8 \%)$ are satisfied or very satisfied with the living conditions.

\section{Table 4}

Assessment of Living Conditions

Assessment of living conditions

Very good 


$\begin{array}{lc}\text { Satisfaction with living conditions } & \\ \text { Very satisfied } & 0.6 \\ & \\ \text { Satisfied } & 0.2 \\ \text { Neither dissatisfied nor satisfied } & 54.3 \\ \text { Unsatisfied } & 39.7 \\ \text { Very dissatisfied } & 5.2\end{array}$

People with disabilities assess living conditions worse than non-disabled people (50\% and $39.7 \%)(\chi 2(6)=17.09, p<.05)$. Consequently, a larger proportion of them are dissatisfied with living conditions ( $50 \%$ and $39.7 \%)(\chi 2(4)=17.09, p<.05)$. The number of persons with disabilities participating in the study and their distribution by municipalities is given in Table \# 1 , Chapter

\section{The Daily Life and Relationships of the Elderly}

Household is one of the main aspects of the living conditions of the elderly. In general, when the elderly do not live alone, their spouses and other adult household members can generate additional sources of income and share the burden of family activities, while lonely elderly are deprived of this opportunity; however, they may want to run their own household independently, but often this does not help their health.

About half (49.1\%) of the elderly are almost unable to support themselves with household chores and less (37.7\%) with households (see table \#5).

\section{Table 5}

Spending on Household Chores and Households (Most Commonly Named Answers)

\begin{tabular}{ll}
\hline Handle in household & 30.4 \\
I find it hard to catch myself & 49.1 \\
I can hardly stand myself & 20 \\
Copying with the household & 37.7 \\
I find it hard to catch myself & 3 \\
\hline
\end{tabular}

The present study also shows that older people do not have frequent social contacts; Nearly half of the elderly rarely interact with neighbors (45.9\%), even fewer with relatives (57.8\%), and even less with friends (80.4\%). This trend is maintained in municipalities; However, it is positive that only $4.3 \%$ of respondents do not have friends and $0.9 \%$ do not have neighbors. It is also noteworthy that according to research data, part of the elderly is often unable to move due to lack of funds, which also affects their social relationships. 


\section{Table 6}

Social Relationships with Neighbors, Relatives and Friends

\begin{tabular}{lccc}
\hline & Neighbors $\%$ & Relatives $\%$ & Friends \% \\
\hline Very often & 1.5 & 0 & 0.4 \\
Quite often & 18.8 & 4.7 & 3.7 \\
Rarely & 45.9 & 57.8 & 80.4 \\
I almost do not go & 33.8 & 36.6 & 11.2 \\
I do not have & 0 & 0.9 & 4.3 \\
\hline
\end{tabular}

Among the respondents as a whole (77.6\%), the elderly rarely go to the city or village center in the municipalities (see table \#6).

Although seniors were recommended to stay home during the COVID-19 pandemic, more than $77.2 \%$ of seniors mostly went shopping on their own and bought the necessary products, and a little less mostly paid utility bills themselves. Most of these activities were assisted by neighbors and relatives (20.9\%), especially in the payment of utility bills (38.6\%).

Table 7

Perform Daily Activities

\begin{tabular}{cc}
\hline \multicolumn{1}{c}{ Daily activities } & $\%$ \\
\hline Purchase the necessary products I mostly go by myself & 77.2 \\
Payment of utility bills I pay mostly myself & 59.7 \\
\hline
\end{tabular}

The interviewed elderly named economic problems in the first place among the difficulties (57.7\%); A small number also called health (11\%) and housing problems (10.1\%) (see table \#7).

Majority of older people have various health conditions; $33 \%$ of respondents visited a medical facility at least once in the previous 12 months. They had to walk to medical facilities or got there using public transport. More than half of them had not always been able to undergo medical examinations prescribed by a doctor due to a lack finances.

It is noteworthy that the biggest problem in all municipalities was named as an economic problem; Given the assessment of the financial problems of the elderly, this result is not surprising (see table \#8).

\section{Table 8}

The Biggest Problems of the Elderly

\begin{tabular}{lc}
\hline \multicolumn{1}{c}{ Problems } & $\%$ \\
\hline Economic problems & 75.7 \\
Health & 9 \\
Social & 3 \\
Access to medical care & 0.4 \\
Housing problems & 6.3 \\
\hline
\end{tabular}

The TV is not a luxury item, and it is available to the vast majority of seniors (91\%), although only a small proportion of respondents - $20 \%$ - have a mobile phone. Also, the number of seniors 
who are computer and internet users is very small, and only a few respondents $(0.6 \%)$ have access to the internet.

People who have a telephone (Spearmen's correlation =.764) and internet and computer (Spearmen's correlation, $=.667 ; p<.05$ ) reported less isolation than people without them; there is a significant correlation between frequency of communication and the level of isolation (Spearmen's correlation $=-.764 ; p<.05$ ). People with better financial resources reported less isolation (Spearmen's correlation $=-.554 ; p<.05)$.

\section{Discussion}

Based on the research, it can be said that COVID-19 in the target municipalities has more or less changed the daily life of the majority of lonely elderly people. The elderly in the target municipalities are well informed about the pandemic, and the elderly receive information through magazines, newspapers, television, and the local government. The information and recommendations provided by the government and relevant structures regarding the pandemic were understandable to almost all respondents.

The study participants' primary income source is social assistance and various pensions; Thus, the elderly people are financially dependent on state aid. None of them receive income from work, and only a few seniors receive some income from selling their own agricultural products. Based on the above, it can be said that the elderly living in the research target municipalities have less opportunity for economic activity. Secondary data from the study indicate that the given condition is prevalent across the country. Given all the above, it is natural that most respondents assess their own economic situation as bad; It is noteworthy that none of them consider their own economic situation very well or well. It should be noted that the financial condition of the target population was challenging before pandemic too.

Although it was recommended for seniors aged 70 and over to stay home during a pandemic, seniors mainly bought food themselves, received a pension, and bought medicines; However, they were also assisted by neighbors, local government, and volunteers. During the pandemic, neighbors turned out to be an essential source of assistance for the elderly, which is not surprising in Georgia and should probably be due to the proximity and close relations of the neighbors. During the pandemic, the elderly received various types of assistance from the local government, which is related to the commitment made by the state during the fight against the pandemic. Based on the survey data, it can be said that the local government in the target municipalities was mobilized to meet the needs of the elderly.

Most of the elderly living in the target municipalities are restricted from traveling due to a lack of funds. This circumstance may harm meeting the daily needs of the elderly and their psychological state and social and political activity. Many international studies indicate that the psychological state of the elderly is affected by their living conditions and social relationships (Sendi \& Filipovich, 2017). Many older people feel excluded and suffer from relationship deficits. They cannot see other people, including family members if they live in another city or country.

Despite the current economic situation, the elderly living in the target municipalities do not have difficulty paying utility bills. Undoubtedly, introducing the rule of subsidizing utility bills by the Government of Georgia has positively contributed to this situation. In this regard, the situation of socially vulnerable families is also somewhat alleviated by the one-time economic assistance programs in the municipal halls. It should be noted that paying gas bills is easier for respondents than electricity. In this respect, the situation in the municipalities is more or less homogeneous, although the best situation is in Bolnisi, and the worst in Tianeti.

In the target municipalities, the elderly have almost no mobile phone, no computer and internet users - only $1 / 5$ of the survey participants have a telephone, and only a few older people have a computer and access to the internet. As technology becomes increasingly important in modern economic and social relations, the lack of technology and the ability to use it further exacerbates the vulnerability of the elderly.

Unfortunately, unlike young people, social media and online platforms have not effectively replaced face-to-face relationships with the elderly. COVID-19 has particularly affected older people who have had major social contacts outside the home, such as community centers, daycare centers, etc. (Armitage \& Nellums, 2020). 
OF PSYCHOLOGY

IN THE $21^{\text {st }}$ CENTURY

Vol. 15, No. 2, 2021

70 https://doi.org/10.33225/ppc/21.15.61

While it is currently unclear what the full extent of the impact of this pandemic will be, its adverse effects on psychological well-being have become apparent. Studies have already noted increased anxiety and depression in the general population, especially those at risk of prolonged blockade. These effects are exacerbated in the elderly, mainly due to severe lock-in, high risk of disease, and lack of social contact (Yang at al., 2020). Previous studies have also stated that even without a crisis period, the elderly population has relatively high rates of depressive symptoms (Li et al., 2014), which is worrying in light of the evidence that those who suffer from mental health conditions are the most vulnerable, most affected.

Studies have shown that depression in the elderly is associated with further cognitive impairment and the risk of Alzheimer's disease. This means that while many societies face an immediate threat to increased mental health, long-term outcomes can be devastating as depression and stress increase the risk of accelerated cognitive impairment and Alzheimer's disease in the older generation. This problem is likely to be exacerbated by the physical limitations people face when moving out of their homes, resulting in fewer individuals having less opportunity to exercise. Research has shown that exercise, even moving a small distance, can have a significant positive effect on the cognitive function of the elderly, especially in those with cognitive impairment or neuropsychiatric disorders (Jedrziewski et al., 2014).

Governments are important to increase comprehensive access to older technologies and relevant digital literacy interventions. This will significantly reduce the negative impact of the pandemic on the elderly. Local governments need to promote the economic activity of the elderly, mainly to make the lifelong learning program more accessible to the elderly. The elderly will have the opportunity to acquire new knowledge and skills, which will make their economic activities more productive.

Local governments must promote social contacts of the elderly and the development of solidarity between generations. It is important to establish senior clubs at the local level, to encourage and support their activities - Discussions on various social and political issues, cultural events, and the elderly. Examples of this are organizing groups of volunteers from high school students to help local single and homeless seniors with household chores and households, ensuring the attendance of seniors at various cultural events, involving seniors in local government work, and more.

It is essential to raise the awareness of the elderly concerning modern technologies - To develop the skills of using mobile phones and the internet. For this purpose, groups of volunteers with the abovementioned young people can be used, and local governments will equip the elderly with the necessary equipment. Volunteers working with the elderly must receive special training on key gerontology issues to communicate with the elderly while respecting and respecting their dignity.

\section{Limitation of the Study}

Due to the use of quantitative methods in the study alone, comprehensive information on several issues could not be obtained; for example, the pandemic changed the lives of the respondents, however, what exactly these changes affected, the research could not cover.

It is necessary to study these topics using mixed methods, which was impossible during the research period (due to the COVID-19 pandemic).

\section{Conclusions}

Overall, the elderly is a fairly vulnerable group in municipalities and across the country. The biggest problem during the pandemic period was a lack of financial resources and social contacts. Because of these challenges, during COVID-19, the elderly became more dependent on others; It became even more difficult for them to cope with daily activities.

There is a positive relationship between limited access to technologies and lack of financial resources that plays a vital role in social relationships among the elderly. Those elderly who cannot afford access to computer/internet and telephone reported higher isolation levels.

The elderly have limited social relationships; They rarely interact with neighbors, much less with relatives, and even less with friends. The elderly rarely go to the city or village center either.

Limited social networking and activities affect the mental health of the elderly. Such a situation is especially noteworthy in a pandemic. Though majority of older people have health-related problems, 
more than half of them could not get medical examinations prescribed by a doctor due to a financial shortage.

\section{Acknowledgements}

The research report has been prepared within the framework of the UN Joint Program "Assisting the Georgian Government and Local Communities in Mitigating the Impact of COVID-19". The research has been supported by the United Nations Population Fund (UNFPA) Country Office in Georgia. The views expressed herein are those of the authors and do not necessarily reflect the views of the United Nations Population Fund (UNFPA).

\section{References}

Adams, K. B., Sanders, S., \& Auth, E. A. (2004). Loneliness and depression in independent living retirement communities: Risk and resilience factors. Aging \& Mental Health, 8, 475-85. http://dx.doi.org/10.1080/13607860410001725054

Affo. M. (2020). How you can still socialize with your friends during COVID-19. Delaware News Journal; 2020. https://eu.delawareonline.com/story/life/2020/03/18/how-you-can-still-socialize-your-friends-duringcovid-19/5069237002/

Armitage R., \& Nellums. L (2020). COVID-19 and the consequences of isolating the elderly. Lancet Public Health, 5, Article e256. https://doi.org/10.1016/S2468-2667(20)30061-X

Ayalon, L., Chasteen, A., Diehl, M., Levy, B. R., Neupert, Sh. D., Rothermund, K., Tesch-Romer, C., \& Wahl, H. (2020). Aging in times of the COVID-19 pandemic: Avoiding ageism and fostering intergenerational solidarity. Journals of Gerontology: Psychological Sciences, 76(2), 49-52. https://doi.org/10.1177/2333721420960259

Blazer, G. B., Hybels, C. F., \& Pieper, C. F. (2001). The association of depression and mortality in elderly persons: A case for multiple, independent pathways. The Journals of Gerontology: Series A, 56, M505-509. https://doi.org/10.1093/gerona/56.8.M505

Boserup. B., McKenney, M., \& Elkbull, A. (2020). Alarming trends US domestic violence during the COVID-19 pandemic. American Journal of Emergency Medicine, 38, 2753-2755. https://dx.doi.org/10.1016\%2Fj.ajem.2020.04.077

De Bruni, B., \& Chitanava, M. (2017). Aging and aging of the population in Georgia http://census.ge/files/results/publication/ge/2.\%20Ageing_GEO_Print\%20_F_0.pdf

Domínguez-Rué, E., \& Linda Nierling, L. (2016). Ageing and technology: Perspectives from the social sciences. Transcript Verlag, Bielefeld.

Friemel, T. N. (2016). The digital divide has grown old: Determinants of a digital divide among seniors. New Media \& Society, 18, 313-331. https://doi.org/10.1177\%2F1461444814538648

Government of Georgia (2019). Ordinance N 2238: National Document on Sustainable Development Goals https://www.matsne.gov.ge/ka/document/view/4732470?publication=0

Jedrziewski, M.K.,Ewbank, D.C., \& Wang, H., \& Trojanowski, J.Q.(2014). The impact of exercise, cognitive activities, and socialization on cognitive function: Results from the national long-term care survey. American Journal of Alzheimer's Disease \& Other Dementias, 29, 372-378.29. https://doi.org/10.1177/1533317513518646

Keberler, B. S., \& Filipovic, H. M. (2017). The relationship of the elderly toward their home and living environment. Urbani Izziv, 28, 96-109. http://www.jstor.org/stable/26266353

National Statistics Office (Geostat) (2016) Population 2014 General Description of Key Outcomes. https://www.geostat.ge/media/4264/angarishi-2016.pdf

Parliament of Georgia (2016). Resolution N 5146-II: Concept of State Policy on Population Aging in Georgia, Legislative Herald of Georgia https://matsne.gov.ge/ka/document/view/3331420?publication=0

Public Defender of Georgia (2019). Parliamentary report - on the situation of the dispute in human rights and freedoms in Georgia. Office of the Public Defender of Georgia http://www.ombudsman.ge/res/ docs/2020040215365449134.pdf 
OF PSYCHOLOGY

IN THE $21^{\text {st }}$ CENTURY Vol. 15, №. 2, 2021

72
Public Defender of Georgia (2018). On the situation of the dispute in human rights and freedoms in Georgia, Office of the Public Defender of Georgia. http:/www.ombudsman.ge/res/docs/2019042620571319466.pdf

Shankar. A., Rafnsson S., \& Steptoe, A. (2015). Longitudinal associations between social connections and subjective well-being in the English longitudinal study of ageing. Psychology \& Health, 30, 686-98. $10.1080 / 08870446.2014 .979823$

Social Service Agency (2020). Number of pensioners and the amount to be paid to them. http://ssa.gov.ge/index.php?lang_id=GEO\&sec_id=1471

Social Service Agency (2020). Number of social package recipients by groups. http://ssa.gov.ge/index.php?lang $\mathrm{id}=$ GEO\&sec_id $=1472$

Sumbadze, N., Kitiashvili, A., Abashidze, T., Zhvania, I. And Makharadze, T. (2020) Health and Social Care for the Elderly in Georgia - Existing Services and Basic Needs - Survey Report https://www.ctc.org.ge/wp-content/uploads/2020/03/Research-Reprot-for-Print-06.03.2020.pdf

UNICEF (2017). Population Welfare Survey United Nations (2002). Political Declaration and Madrid International Plan of Action on Aging. https://www.un.org/en/events/pastevents/pdfs/Madrid_plan.pdf

United Nations (2015). Transforming our World: The 2030 Agenda for Sustainable Development, A/RES/70/1. https://www.un.org/ga/search/view_doc.asp?symbol=A/RES/70/1\&Lang=E

United Nations (2020). Secretary-General: Impact of the coronavirus disease (COVID-19) on the enjoyment of all human rights by older people. https://undocs.org/A/75/205

Viera, C, M., Franco, O, H., Resprepo, C, G., \& Abel, T. (2020) COVID-19: The forgotten priorities of the pandemic. Maturitas, 2, 173-190. https://doi.org/10.1177/2516602620937932

WHO (2017). Global Strategy and Action Plan on ageing and Health https://www.who.int/ageing/WHOGSAP-2017.pdf?ua=1

WHO (2020). Supporting older people during the COVID-19 pandemic is everyone's business. WHO. https:// www.euro.who.int/en/health-topics/health-emergencies/coronavirus-covid-19/news/news/2020/4/ supporting-older-people-during-the-covid-19-pandemic-is-everyones-business

Windle, G., \& Woods, R. (2004). Variations in subjective well-being: The mediating role of a psychological resource. Ageing and Society, 24, 583-602. https://doi.org/10.1017/S0144686X04002107

Yang, Y., Li, W., Zhang, Q., Zhang L, Cheung T, \& Xiang Y, T. (2020). Mental health services for older adults in China during the COVID-19 outbreak. Lancet Psychiatry, 7, Article e19. https://doi.org/10.1016/S2215-0366(20)30079-1

Received: November 18, 2021

Accepted: December 22, 2021

Cite as: Kitiashvili, A., \& Makharadze, T. (2021). Financial and social challenges facing pensioners living alone below the poverty line during the Covid-19 period: The case of Georgia. Problems of Psychology in the $21^{\text {st }}$ Century, 15(2), 61-72. https://doi.org/10.33225/ppc/21.15.61

Anastasia Kitiashvili

(Corresponding author)
PhD, Professor, Ivane Javakhishvili Tbilisi State University, 1 Chavchavadze

avenue, 0179 Tbilisi, Georgia.

E-mail: anastasia.kitiashvili@tsu.ge

Website: https://www.tsu.ge/en
Tamar Makharadze 